\title{
Wykorzystanie zmodyfikowanego algorytmu Fruchtermana-Reingolda w celu identyfikacji potencjalnych brokerów w sieci organizacyjnej
}

\section{Using modified Fruchterman-Reingold algorithm in the process of potential brokers identification in the organisational network}

\author{
Piotr Andrzejak \\ Uniwersytet Ekonomiczny we Wrocławiu, e-mail: piotr.andrzejak@ue.wroc.pl; ORCID:0000-0002-1141-0027
}

\begin{abstract}
Streszczenie
Umiejętność szybkiego zlokalizowania potencjalnie istotnych osób w organizacji stale nabiera znaczenia. Brokerzy, określani w analizie sieciowej mianem kluczowych graczy, bez wątpienia stanowią osoby, na których stratę żadne przedsiębiorstwo nie chce i w warunkach nieustająco rosnącej konkurencji nie może sobie pozwolić. W organizacjach liczących nierzadko setki, tysiące, a nawet dziesiątki tysięcy pracowników znalezienie osób pełniących funkcję pośredników tradycyjnymi metodami należy do niemałych wyzwań. W niniejszym artykule zaprezentowano jedno z podejść pozwalających skrócić czas i ograniczyć prawdopodobieństwo wytypowania niewłaściwych osób. Celem artykułu jest analiza problemu identyfikacji potencjalnych brokerów przy wykorzystaniu wizualizacyjnych algorytmów opartych na grafach, a szczególnie zaprezentowanie zmodyfikowanej wersji znanego algorytmu Fruchtermana-Reingolda, który zakłada uwypuklenie położenia potencjalnych brokerów w sieci nieformalnej.
\end{abstract}

Słowa kluczowe: broker, analiza sieci organizacyjnych, grafowe algorytmy wizualizacyjne.

\begin{abstract}
Quick identifying potentially significant persons within the organisation structure is constantly becoming more and more important. Key players such as brokers are with no doubt one of the most important actors, loss of which cannot be acceptable by the organisation itself, especially nowadays, when the competition on the market is growing rapidly. Enterprises having more than thousands of employees struggle to detect the most valuable persons using traditional approaches such as managerial surveys. The paper presents an approach that allows to shorten time needed to identify potential key brokers, and reduce the probability to make wrong guesses. The aim of this article is to analyze the problem of potential brokers identification with the usage of graph visualization algorithms. The paper presents modified Fruchterman-Reingold algorithm, which emphasizes the positions of brokers in the informal network.
\end{abstract}

Keywords: broker, organisational network analysis, graph visualization algorithms. 


\section{Wstęp}

W związku z niewątpliwie istotnym znaczeniem brokerów potrzebne wydają się skuteczne sposoby szybkiego i w miarę bezbłędnego identyfikowania potencjalnych brokerów w sieci organizacyjnej. Analiza sieci społecznych (SNA, Social Network Analysis) dostarcza pewnych technik, dzięki którym struktura sieci może być empirycznie opisywana, wizualizowana, a następnie analizowana pod kątem identyfikacji kluczowych graczy [Scott 2000]. Niemniej jednak już Borgatti zwracał uwagę na to, iż istniejące miary i algorytmy nie $\mathrm{w}$ pełni rozwiązują problem identyfikowania kluczowych graczy, w tym również brokerów [Borgatti 2006]. Koreańscy badacze: S. Kim, E. Suh oraz Y. Jun, próbowali budować system mający na celu skuteczne pośredniczenie w wymianie wiedzy [Kim, Suh, Jun 2011]. W swoim artykule zwracali uwagę na problemy związane z poprawnym wytypowaniem osób mogących odegrać rolę brokerów. Obecnie prowadzone są badania nad skutecznymi sposobami detekcji kluczowych osób, w tym brokerów [Ramos-Vidal, 2017], co wskazuje na wciąż istniejącą lukę badawczą. W niniejszym artykule zaprezentowane zostanie wykorzystanie algorytmu Fruchtermana-Reingolda [Fruchterman, Reingold 1991] w identyfikowaniu kluczowych brokerów. Ponadto ukazana zostanie zmodyfikowana wersja powyższego algorytmu, mająca na względzie wyraźniejsze ukazanie położenia brokerów w sieci nieformalnej, co stanowi główny cel opracowania.

W artykule przedstawiono najpopularniejsze grafowe algorytmy wizualizacyjne oparte na analogiach dotyczących fizycznych oddziaływań, wskazując, skąd się wywodzi idea ich zastosowania. Położono nacisk na dokładniejsze opisanie wyżej wymienionego algorytmu Fruchtermana-Reingolda. W dalszej części ukazano modyfikację tego algorytmu przez zastosowanie dodatkowej siły analogicznej do oddziaływań elektrostatycznych. Następnie na przykładzie przeanalizowanej organizacji z branży usługowej pokazano rzeczywiste sieci nieformalne wyrysowane przy użyciu klasycznej wersji algorytmu Fruchtermana-Reingloda, jak również przy wykorzystaniu jej zmodyfikowanej wersji.

\section{Brokerzy}

Pojęcie brokerstwa w analizie sieci społecznych obecne jest stosunkowo długo. Już w 1979 roku Linton C. Freeman próbował odpowiedzieć na pytanie, co to znaczy być osobą o wysokim współczynniku centralności w sieci i jak różne role sieciowe możemy wyróżnić, bazując na cechach zachowania osoby w omawianej strukturze [Freeman 2004]. Zaproponował trzy interpretacje pojęcia centralności, z którego ostatnie odnosi się do terminu „broker”:

- bycie aktywnym w obrębie sieci, czyli utrzymywanie relatywnie dużej liczby kontaktów,

- bycie efektywnym bądź niezależnym dzięki niedalekim dystansom do pozostałych wierzchołków w sieci,

- $\quad$ bycie ważnym węzłem pośredniczącym, czyli leżącym na wielu ścieżkach pomiędzy niezależnymi węzłami.

Zaprezentowana powyżej klasyfikacja nie wyczerpuje oczywiście wszystkich możliwości, jednakże podejście Freemana jest obecnie dość powszechnie stosowane w analizie sieciowej. W niniejszym opracowaniu skupimy się na trzecim opisie, mogącym być utożsamianym z definicją Burta, który brokerstwo odnosi do szczególnego położenia w kontekście sieci. W tej interpretacji broker ma za zadanie łączyć grupy, niemające innych bezpośrednich połączeń [Burt 1992]. Bazując na tym stwierdzeniu, należy stwierdzić, że brokerstwo dostarcza korzyści dla jednostek, opierając się na następującej idei: nieredundantne osoby stanowią źródła unikalnej informacji, która może być użyta przez brokera dla uzyskania osobistej przewagi poprzez wzrost względnego kapitału społecznego w omawianej organizacji [Burt 2005]. Samo pojęcie kapitału społecznego wiąże się z położeniem danej osoby w strukturze relacji [Burt 2004] i stanowi przeciwwagę do terminu kapitału ludzkiego [Schulz 1961] jako zbioru cech danej osoby stanowiących przewagę konkurencyjną. Wśród cech wyróżniających brokera w sieci organizacyjnej możemy wymienić:

- ułatwianie dostępu do nowych informacji lub zasobów,

- umożliwianie transferu wiedzy,

- koordynowanie pracy w obrębie sieci.

Brokerzy są uważani za kluczowych graczy w tym kontekście, iż wyrugowanie ich z sieci powoduje nierzadko znaczny spadek wydajności, a także ogranicza możliwości sieci do sprawnego funkcjonowania [Borgatti 2006].

Na szczególną rolę brokerów sieciowych zwracają także uwagę Kauffeld-Monz i Fritsch [Fritsch, Kauffeld-Monz 2010], skupiając się co prawda na pojęciu brokerów wiedzy, niemniej jednak ich podejście można uogólniać również na inne obszary aniżeli wiedza. W rozważanej przez nich perspektywie kluczowe wydaje się umiejscowienie pewnych węzłów w strukturze nieformalnej sieci tak, aby ułatwić, względnie umożliwić, dyfuzję wiedzy pomiędzy jednostkami. Podobnie rozważając pojęcie innowacyjności korporacyjnej, najpierw Hargadon i Sutton [1997], a następnie m.in. Obstfeld [2005] i Aral wraz z van Alstynem [2011] eksponowali znaczenie brokerów, kładąc nacisk na wykorzystanie brokerów wiedzy dla wspierania innowacyjnych zachowań jednostek w obrębie organizacji. Również Dobbins [Dobbins i in. 2009] sugerował, iż istnienie oraz odpowiednie umiejscowienie w strukturze sieci pewnych osób mających stosunkowo bogate doświadczenie i obszerną wiedzę $\mathrm{w}$ danym kontekście poprawia możliwości rozwoju jednostek, a co za tym idzie - wspiera zdolność organizacji do samodoskonalenia.

\section{Grafowe algorytmy wizualizacyjne}

Jednym z najbardziej intuicyjnych sposobów prezentowania sieci organizacyjnych jest zastosowanie wizualizacji grafowej. Poza oczywistą prostotą interpretacyjną, w myśl której relacje pomiędzy poszczególnymi węzłami odwzorowują związki pomiędzy osobami w rzeczywistej organizacji, otrzymujemy ogromne możliwości związane z mnogością sposobów rozłożenia poszczególnych elementów grafu na płaszczyźnie. Jednakże wspólną, pożądaną cechą wizualizacji grafowej pozostaje czytelność i przejrzystość odwzorowania, która sprowadza się do pewnych uniwersalnych odczuć estetycznych, m.in. takich jak ograniczenie liczby przecięć pomiędzy krawędziami grafu, maksymalne wykorzystanie dostępnej powierzchni, nienakładanie się poszczególnych węzłów [Dong i in. 2014]. 
Aby zmapować relacyjne struktury, takie jak grafy, próbowano stosować wiele różnych rodzajów grafowych algorytmów wizualizacyjnych. Niemniej jednak ze względu na zdolność tworzenia grafów spełniających podstawowe kryteria estetyczne wyszczególnione powyżej algorytmy oparte na analogiach dotyczących fizycznych oddziaływań (force-directed graph drawing algorithms) są najpowszechniej stosowane [Kobourov 2012]. Historycznie jednym z pierwszych algorytmów tego typu jest ten pochodzący od Tutte'a [1963], oparty na reprezentacji barycentrycznej. Bardziej tradycyjne podejścia obejmują interpretacje pochodzące od Eadesa [1984] bądź Fruchtermana i Reingolda [1991] - obie wykorzystują analogię do prawa Hooke'a, gdzie relacje są traktowane jako sprężyny, zakłada się więc istnienie siły przyciągającej pomiędzy każdymi dwoma węzłami mającymi wspólną krawędź. Ponadto zakłada się istnienie sił odpychających pomiędzy każdymi dwoma węzłami, abstrahując od tego, czy węzły te są połączone.

Innym popularnym algorytmem stosującym podobne zależności fizyczne jest algorytm Kamady-Kawaiego [Kamada, Kawai 1989], w którym wylicza się siły oddziałujące pomiędzy węzłami, stosując miarę odległości geodezyjnej pomiędzy nimi. W ogólności we wszystkich algorytmach wykorzystujących analogię do wielkości fizycznych związanych z siłami oddziaływań stosuje się funkcję mapującą każde odwzorowanie graficzne na pewną liczbę $\mathrm{w}$ przestrzeni $\mathrm{R}+$, będącą $\mathrm{w}$ warstwie interpretacyjnej liczbą tożsamą z wielkością energii układu bądź jego temperaturą. Funkcja jest konstruowana w taki sposób, że niska energia, względnie temperatura, odnosi się do układu, w którym odległości pomiędzy węzłami są relatywnie blisko pewnych arbitralnie wyspecyfikowanych wielkości, np. dąży się do uzyskania możliwie równych długości krawędzi [Bertault 2000]. Jeśli chodzi o węzły bezpośrednio ze sobą niepołączone, próbuje się ukazać symetrie w grafie. Iteracyjny charakter algorytmów pozwala na wyliczanie wartości energii (temperatury) po każdej z iteracji, istotą działania zatem jest znalezienie takiego układu węzłów i relacji, aby uzyskać minimum (najczęściej lokalne) dla funkcji energii (temperatury) [Kobourov 2012].

Należy zwrócić uwagę na pewne ograniczenia związane ze stosowaniem grafowych algorytmów wizualizacyjnych. Jedno z najpoważniejszych wyzwań stanowi ryzyko wpadania układu w licznie istniejące minima lokalne. Dodatkowo dla stosunkowo dużych grafów (liczących więcej niż kilkaset wierzchołków) czas wykonania algorytmu znacznie się wydłuża [Dong i in. 2014]. Ponadto istotnym problemem może okazać się duża liczba przecięć pomiędzy krawędziami, potrafiąca skutecznie zniekształcić końcowy efekt. Dlatego też wykorzystuje się różne mniej lub bardziej wyrafinowane metody pozwalające na jak najlepsze wyeliminowanie przecięć z ostatecznego układu. W tym celu stosuje się m.in. algorytmy genetyczne czy też symulowane wyżarzanie [Bertault 2000]. Z drugiej strony, ważną zaletę stosowania omawianej grupy algorytmów stanowi ich prostota implementacyjna oraz duża powtarzalność pewnych cech, pomimo startowania z losowego rozmieszczenia węzłów na płaszczyźnie. Tę powtarzalność pewnych cech układu można próbować wykorzystać do identyfikowania potencjalnych brokerów w sieci.

\subsection{Klasyczny algorytm Fruchtermana-Reingolda}

Klasyczny algorytm Fruchtermana-Reingolda przedstawiony został po raz pierwszy w 1991 roku i od tego czasu doczekał się wielu modyfikacji i usprawnień [Dong i in. 2014].

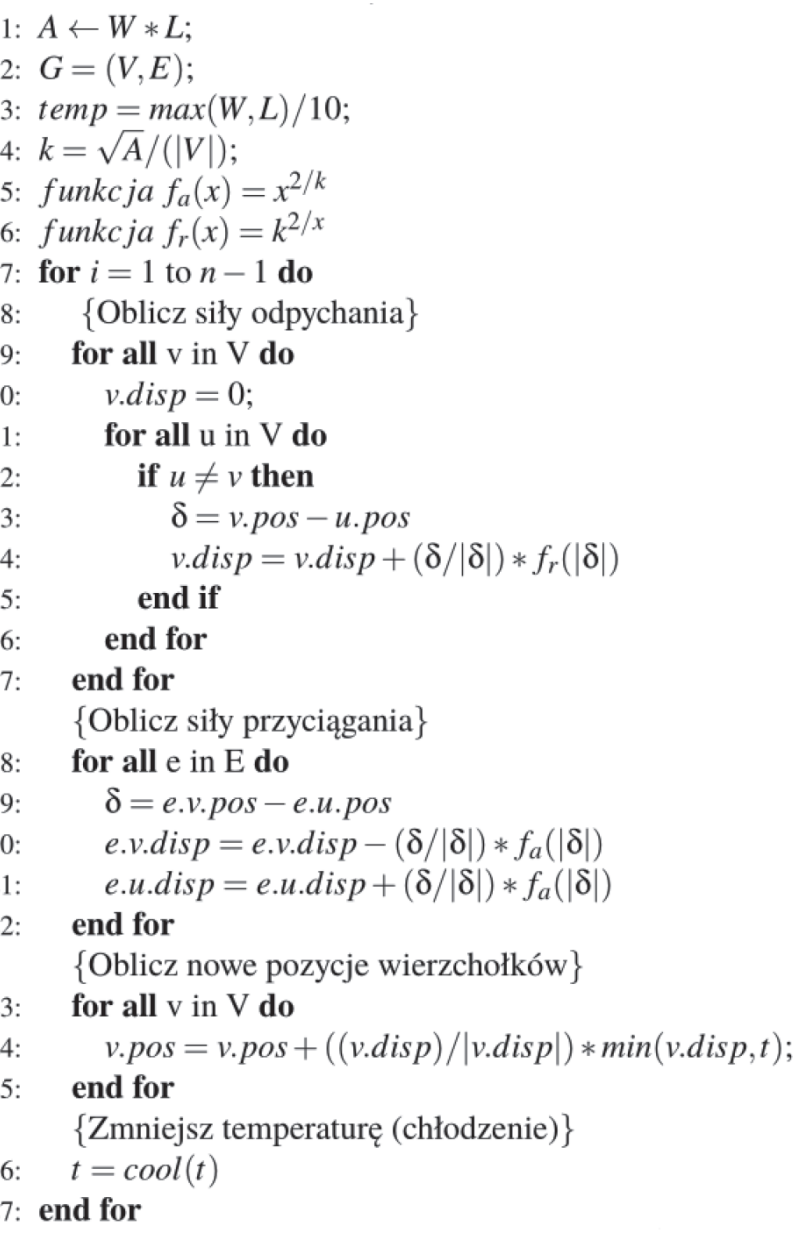

Listing 1: Algorytm Fruchtermana-Reingolda

Źródło: opracowanie własne na podstawie [Kobourov 2012].

Opis algorytmu jest następujący. Na początku współrzędne wierzchołków inicjalizowane są losowymi wartościami, przy czym wielkości te muszą znajdować się w obrębie prostokąta (oznaczenie $A$ ), z arbitralnie określoną długością i szerokością, oznaczoną odpowiednio przez $L$ oraz W. Temperatura jest inicjalizowana wartością równą dziesiątej części większej z wielkości $L$ i $W$. Obliczony zostaje maksymalny krok przesunięcia - $k$. Kolejną fazą jest wykonywanie iteracji aż do osiągnięcia warunku stopu oznaczonego przez temperaturę minimalną lub zadaną maksymalną liczbę iteracji. Każda iteracja składa się z poniższych kroków i jest wykonywana dla każdego z wierzchołków grafu:

1. Obliczenie wektorów przesunięć w odniesieniu do pozostałych wierzchołków (odpychanie).

2. Obliczenie wektorów przesunięć dla każdej pary wierzchołków połączonych bezpośrednio krawędzią (przyciąganie). 
3. Wyznaczenie nowych współrzędnych wszystkich wierzchołków (akumulacja przesunięć z dwóch wcześniejszych punktów).

4. Zmiana (zmniejszenie) temperatury układu (chłodzenie).

\subsection{Modyfikacja algorytmu Fruchtermana-Reingolda}

Pomimo otrzymywania stosunkowo dobrych rezultatów - węzły są rozłożone równomiernie, można zauważyć wyróżnione komponenty spójności - brak jest wyraźnie odseparowanych, a jednocześnie łączących poszczególne grupy węzłów. Tym samym bez odwoływania się do przeprowadzania dogłębnej analizy numerycznej, zatem schodząc na poziom wskaźników liczbowych, takich jak na przykład centralność, jest niezwykle trudno odpowiedzieć na pytanie: któremu z wyrysowanych węzłów można z dużą dozą prawdopodobieństwa przypisać rolę brokerską? Idea mogąca przynieść jakościową poprawę polega na wprowadzeniu dodatkowego oddziaływania na wszystkie węzły w sieci nieformalnej. Inspiracją do zdefiniowania takiego typu interakcji stanowi siła opisana przez znakomitego fizyka francuskiego Charlesa Coulomba. Pomysłem na usprawnienie procesu identyfikacji kluczowych brokerów jest wprowadzenie do omawianego w poprzednim ustępie algorytmu Fruchtermana-Reingolda sił elektrostatycznych. Ze względu na naturę omawianego problemu, w którym istotne jest odseparowanie pewnych grup węzłów i wyraźne ukazanie węzłów pośredniczących, zdecydowano się na stosowanie umownego oznaczenia wszystkich węzłów ładunkami elektrycznymi o takim samym znaku. Wartość siły oddziaływania elektrostatycznego dwóch ciał dana jest powszechnie znanym wzorem:

$$
F=k \frac{q_{1} q_{2}}{r^{2}}
$$

gdzie przez $k$ oznaczono stałą oddziaływań ładunków elektrycznych, przez $q_{1}, q_{2}$ wielkość ładunków tych ciał, natomiast przez $r$ odległość pomiędzy tymi dwoma ciałami. Analizując ten stosunkowo prosty wzór, przekonujemy się, iż najistotniejszym wyzwaniem wydaje się określenie wartości ładunków dla poszczególnych węzłów. Ponieważ termin brokerstwa nierzadko odnosi się do pojęcia miary centralności bycia pomiędzy (betweenness) [Creswick, Westbrook 2010; Balkundi i in. 2009], w niniejszej pracy zdecydowano się właśnie na jej wykorzystanie jako analogii do wartości ładunku elektrycznego poszczególnego węzła.

Modyfikacja algorytmu Fruchtermana-Reingolda została przedstawiona na poniższym listingu:

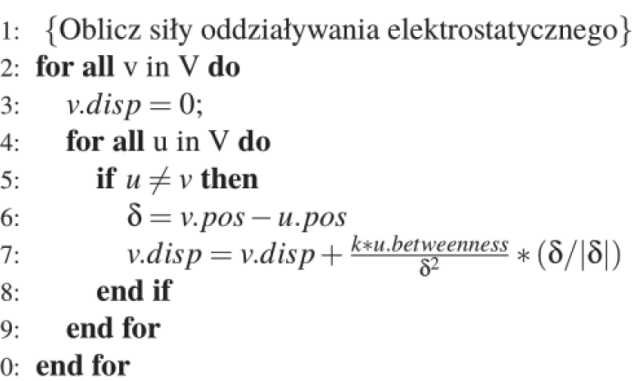

Listing 2: Wyliczenie sił elektrostatycznych (odpychających)

Źródło: opracowanie własne.

Umiejscowienie powyższego fragmentu w oryginalnym algorytmie Fruchtermana-Reingolda przedstawionym na listingu 1 ma miejsce w 8 linii. Idea przemawiająca za możliwym korzystnym wpływem opisanej powyżej modyfikacji zakłada, iż niska wartość centralności pomiędzy danego węzła tylko w nieznaczny sposób spowoduje dodatkowe przesunięcia innych węzłów, znaczna wartość betweenness zaś wymusi dodatkowe odpychanie innych węzłów przez potencjalne węzły brokerskie.

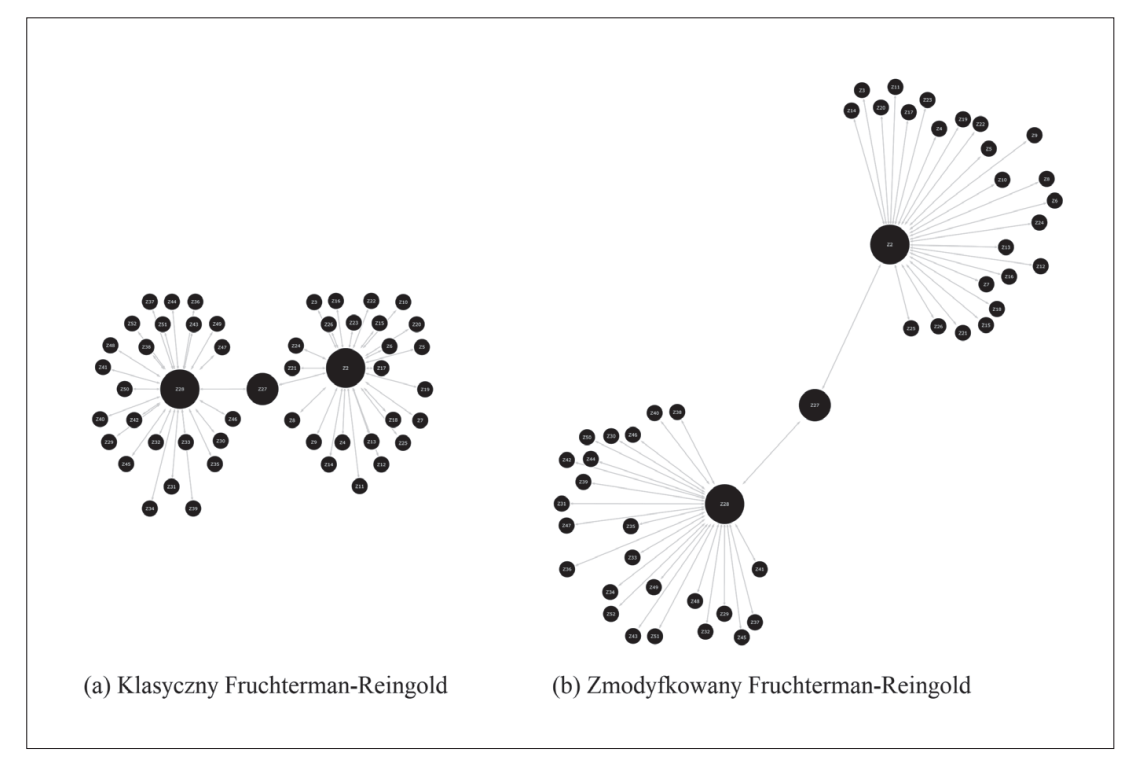

Rysunek 1. Porównanie działania klasycznego algorytmu Fruchtermana-Reingolda oraz zmodyfikowanego poprzez dodanie dodatkowej siły elektrostatycznej (odpychającej)

Źródło: opracowanie własne na podstawie badań. 
Rysunek 1 prezentuje hipotetyczny układ węzłów wyrysowany na płaszczyźnie bez opisanej powyżej modyfikacji algorytmu Fruchtermana-Reingolda i z tą modyfikacją.

\section{Analiza}

Badanie zostało przeprowadzone przy użyciu systemu Netwisor $^{1}$, który jest narzędziem przeznaczonym do analizy sieci organizacyjnych. Wszystkie wizualizacje oraz analiza danych użytych w niniejszym artykule zostały wykonane przy użyciu systemu Netwisor. W studium przypadku wykorzystano dużą firmę działającą w branży. Kwestionariusz skierowano do 819 osób i uzyskano zwrotność na poziomie 76\%. Umieszczone na wizualizacjach symbole pracowników z powodu konieczności anonimizacji danych wprowadzone zostały jedynie dla celów publikacji.

Rysunek 2 pokazuje niezmienniczość pewnych cech układu węzłów pomimo startowania algorytmu z losowymi pozycjami poszczególnych węzłów. Można zauważyć, iż węzły brokerskie (Z3041, Z3090, Z4046) w dwóch przedstawionych wywołaniach algorytmu charakteryzują się podobną pozycją względem innych węzłów sąsiadujących.

Wizualizacje przedstawione na rys. 3 pokazują analizowaną organizację przedstawioną za pomocą klasycznego algoryt-

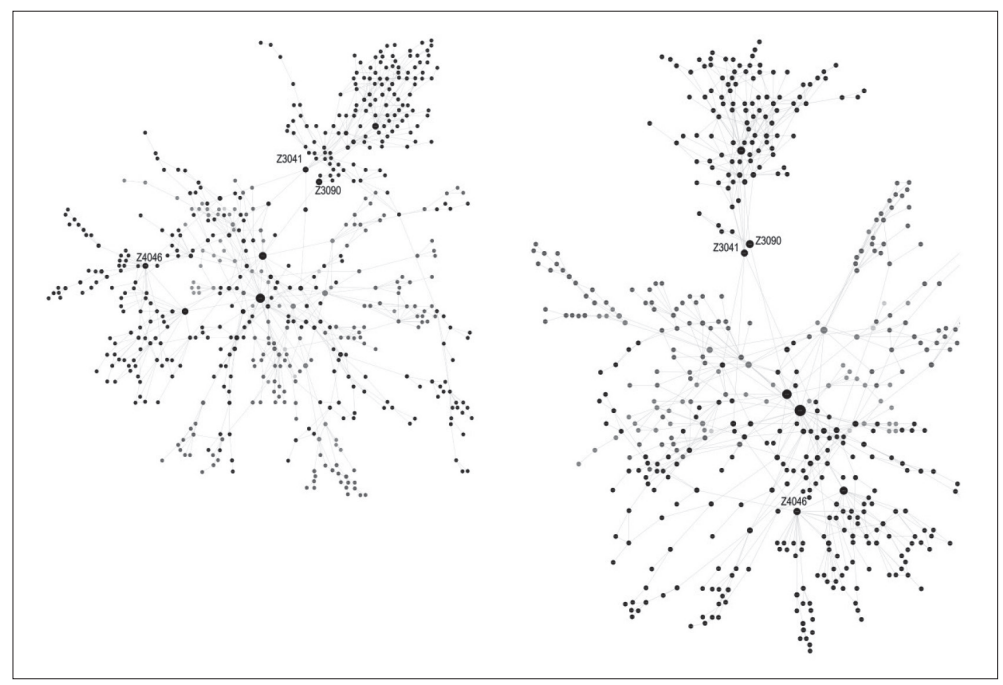

Rysunek 2. Powtarzalność pewnych cech układu. Pozycje trzech brokerów w dwóch wywołaniach algorytmu Fruchtermana-Reingolda. Sieć przepływu informacji

Źródło: opracowanie własne na podstawie badań.

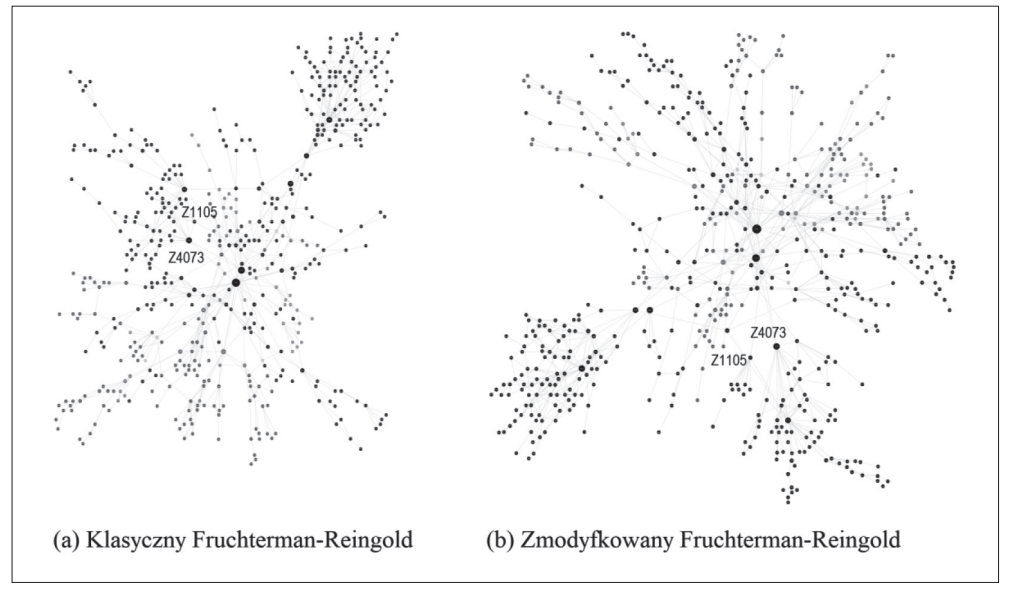

Rysunek 3. Klasyczny algorytm Fruchtermana-Reingolda vs wersja zmodyfikowana o dodatkowe siły elektrostatyczne (odpychające)

Źródło: opracowanie własne na podstawie badań.

${ }^{1}$ System Netwisor jest autorskim systemem analizy sieci organizacyjnych, który umożliwia prowadzenie badań przez prowadzenie kwestionariuszy online, przetwarzanie analityczne na podstawie miar sieciowych oraz wizualizację sieci społecznych. System Netwisor opiera się zarówno na algorytmach autorskich wykorzystujących teorię grafów, jak i na popularnych algorytmach wykorzystywanych między w innymi w projektach badawczych Uniwersytetu Stanforda w ramach szerszego projektu SNAP - Stanford Network Analysis Project. Więcej zob. na stronie http://snap. stanford.edu/. 
mu Fruhtermana-Reingolda oraz przy wykorzystaniu jego zmodyfikowanej wersji. Dostrzegalne jest większe rozsunięcie węzłów. Przy czym węzły o niskiej wartości współczynnika centralności pomiędzy są w podobnych odległościach od siebie zarówno na rysunku przedstawiającym klasyczną wersję algorytmu, jak i na rysunku z wersją zmodyfikowaną - vide grupa w prawym górnym rogu na rysunku $a$ i odpowiadająca jej grupa znajdująca się w lewym dolnym rogu na rysunku $b$. Można także zauważyć, że istotnie na przykład węzły Z1105 oraz Z4073 są wyraźniej odseparowane od swoich bezpośrednich sąsiadów na wizualizacji prezentującej zmodyfikowaną wersję algorytmu Fruchtermana-Reingolda.

Należy zwrócić uwagę na odpowiednie dobranie wartości współczynnika $k$ ze wzoru (1). Jego zbyt niska wartość praktycznie nie powoduje żadnych widocznych różnic w działaniu algorytmu. Zbyt wysoka zaburza całkowicie strukturę. Empirycznie zbadano, iż wartości w zakresie kilku tysięcy prowadzą do uzyskiwania estetycznych i pożądanych rezultatów dla rozważanego problemu identyfikacji potencjalnych brokerów.

\section{Podsumowanie}

Zastosowanie grafowych algorytmów wizualizacyjnych wydaje się skutecznym sposobem na identyfikowanie potencjalnych brokerów w sieci organizacyjnej. Zaprezentowany w niniejszym opracowaniu algorytm umożliwia uzyskiwanie powtarzalnych rozmieszczeń węzłów pośredniczących, eksponując je przy tym odpowiednio. Omawiane rozwiązanie pozwala rozpoznawać kluczowe osoby w sieci bez konieczności wnikania w analizę kontekstu, w jakim rozważana jest dana organizacja. Jedną z możliwych aplikacji może być uwzględnienie algorytmu w okresowej ocenie potencjału ludzkiego oraz przede wszystkim do identyfikacji osób istotnych z punktu widzenia dyfuzji wiedzy, ulepszenia komunikacji czy też zwiększenia skuteczności we wdrażaniu innowacji w organizacji. Ponadto $\mathrm{w}$ artykule pokazano, iż $\mathrm{w}$ grafowych wizualizacjach wciąż tkwi niewykorzystany potencjał - w związku z tym autor niniejszego opracowania zamierza nadal prowadzić badania w tym zakresie.

W zależności od potrzeb badacza inne cechy niż brokerstwo mogą stanowić istotę prowadzonych badań. Modyfikacje istniejących algorytmów wizualizacyjnych oferują $\mathrm{w}$ zasadzie nieograniczone możliwości prezentowania sieci nieformalnych. Niemniej jednak kluczowe z pewnością jest odpowiednie dobranie wizualizacji do natury rozważanego problemu zarządczego. Świadomość dodatkowych miar, zależności czy też cech immanentnych sieci, między innymi, takich jak pojęcie centralności, może przyczynić się do podniesienia jakości dostarczanych rozwiązań.

\section{Literatura}

Aral S., Alstyne M. van, 2011, The Diversity-bandwidth Trade-off, American Journal of Sociology, vol. 117, no. 1.

Balkundi P., Barsness Z., Michael J.H., 2009, Unlocking the influence of leadership networks structures on team conflict and viability, Small Group Res, 40, s. 301-322.
Bertault F., 2000, A force-directed algorithm that preserves edge-crossing properties, Department of Computer Science and Software Engineering, University of Newcastle, Callaghan, 2308 NSW, Australia.

Borgatti S.P., 2006, Identifying sets of key players in social network, Comput Math Organ Th, 12:21.

Burt R.S., 1992, Structural Holes: the Social Structure of Competition, Harvard University Press, Cambridge, Massachusetts.

Burt R.S., 2004, Structural holes and good ideas, Am J Sociol, 110, s. 349-399.

Burt R.S., 2005, Brokerage and Closure: an Introduction to Social Capital, Oxford University Press, New York.

Creswick N., Westbrook J., 2010, Social network analysis of medication adviceseeking interactions among staff in an Australian hospital, Int J Med Inform, 14, s. 735-758.

Dobbins M., Robeson P., Ciliska D., Hanna S., Cameron R., O'Mara L. et al., 2009, A description of a knowledge broker role implemented as part of a randomized controlled trial evaluating three knowledge translation strategies, Implementation Science, 4, 23.

Dong W., Fu X., Xu G., Huang Y., 2014, An Improved Force-Directed Graph Layout Algorithm Based on Aesthetic Criteria, Springer.

Eades P., 1984, A heuristic for graph drawing, Congressus Numerantium, 42, s. 149-160.

Freeman L.C., 2004. The Development of Social Network Analysis, 205 pp. Vancouver: Empirical Press. [A history of social network analysis as a scientific endeavour].

Fritsch M., Kauffeld-Monz M., 2010, The impact of network structure of social network analysis in the context of regional innovation networks, The Annals of Regional Science, vol. 44.

Fruchterman T.M.J., Reingold E.M., 1991, Graph drawing by forcedirected placement, Softw.-Pract. Exp., 21(11), s. 1129-1164.

Hargadon A., Sutton R.I., 1997, Technology brokering and innovation in a product development firm, Administrative Science Quarterly, vol. 42 .

Kamada T., Kawai S., 1989, An algorithm for drawing general undirected graphs, Inform. Process. Lett., 31, s. 7-15.

Kim S., Suh E. Jun Y., 2011, Building a Knowledge Brokering System using social network analysis: A case study of the Korean financial industry, Expert Systems with Applications, vol. 38(12), s. $14633-14649$.

Kobourov S.G., 2012, Spring embedders and force directed graph drawing algorithms arXiv preprint arXiv:1201.3011. URL: http://arxiv. org/abs/1201.3011.

Obstfeld D., 2005, Social networks, the Tertius Iungens orientation, and involvement in innovation, Administrative Science Quarterly, vol. 50 .

Ramos-Vidal I., 2017, Detecting key actors in interorganizational networks, Cuadernos de Gestión, 17. 10.5295/cdg.140512ir.

Schulz T., 1961, Investment in human capital, Am Econ Rev, 51, s. 1-17.

Scott J., 2000, Social Network Analysis: a Handbook, 2nd edition, Sage, London.

Tutte W.T., 1963, How to draw a graph, Proc. London Math. Society, 13(52), s. 743-768. 